\title{
In Vivo Inhibition of Nitric Oxide Synthase by Bisisothiouronium and Bisguanidinium Salts
}

\author{
Monique Roch-Arveiller ${ }^{1}$, Corinne Regnault ${ }^{1}$, Jean-Paul Giroud ${ }^{1}$, Georges Morgant ${ }^{2}$, Jean-Charles Lancelot ${ }^{3}$, \\ Carmela Saturnino ${ }^{3}$, Daniel Perrine ${ }^{4}$ and Dung Nguyen Huy ${ }^{2}$
}

1 CNRS URA 1534, Laboratoire de Pharmacologie, Hôpital Cochin, Paris, France

${ }^{2}$ Laboratoire de Chimie Physique, Minérale et Bioinorganique, Faculté de Pharmacie Paris XI, Châtenay-Malabry, France

${ }^{3}$ Laboratoire de Chimie Thérapeutique, Faculté de Pharmacie, Caen, France

${ }^{4}$ Laboratoire de Parasitologie, Faculté de Pharmacie, Caen, France

Summary: The ability of two S,S'-(alkane-1, $\omega$-diyl) bisisothiouronium dibromides, three N,N'-(alkane-1, $\omega$-diyl) bis guanidinium dinitrates and $\mathrm{N}, \mathrm{N}^{\prime}$-bis (3-guanidinopropyl)piperazine dinitrate to inhibit constitutive (i. e. endothelial and neuronal forms) and inducible forms of nitric oxide synthases has been evaluated in vivo. These compounds, synthesized by two of us (J. C. L. and C. S.), have been tested in vivo; they were administered simultaneously with an irritant (carrageenan $\lambda$ ) into the pleural cavity. The amount of nitrites collected 0.5 and 7 hours after this injection can be considered as an indicator of nitric oxide (NO) production. According to previous data, the first harvesting time can be related to activation of constitutive NO synthases and the second to activation of inducible NO synthases.

These substances significantly inhibited nitrite production as did 2-methyl-2-thiopseudourea sulphate, previously described as a potent inhibitor of NO synthases and considered as the reference compound.

The inhibiting effect varied according to the chemical structure of the compounds. Results were significantly different from controls at $0.5 \mathrm{~h}$ only with the S,S'-(octane-1,8-diyl) bisisothiouronium dibromide and the S,S'(nonane-1,9-diyl) bisisothiouronium dibromide at the highest concentration, N,N'-(heptane-1,7-diyl) bisguanidinium dinitrate and $\mathrm{N}, \mathrm{N}$-bis (3-guanidinopropyl)piperazine dinitrate. At $7 \mathrm{~h}$, all the results were significantly different from controls, with a major effect observed with $\mathrm{N}, \mathrm{N}^{\prime}$-(heptane-1,7-diyl) bisguanidinium dinitrate.

The most active substances exerted similar effects to the reference substance.

\section{Introduction}

Nitric oxide (NO), a small membrane permeable gas, is enzymatically formed from a terminal guanidino nitrogen of $L$-arginine (1) by a family of three distinct NO synthase isoenzymes (2) and plays several physiological roles (3). In this way, enhanced formation of NO following the induction of a distinct isoform of inducible NO synthase has been implicated in the pathogenesis of a number of inflammatory reactions and, consequently, inhibitors of inducible NO synthases may have therapeutic potential (4).

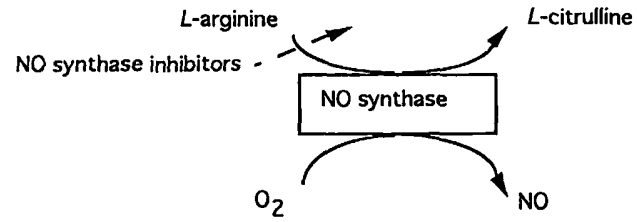

As NO is derived from the guanidino group of $L$-arginine (fig. 1, a), several strong inhibitors of NO synthases have been obtained by addition of a functional group on the molecule or by substitution of one of the guanidino nitrogens. In that way,

i) $\mathrm{N}(\omega)$-monomethyl- $L$-arginine (fig. $1, \mathrm{~b}$ ), a non-selective NO synthase inhibitor,

ii) $\mathrm{N}(\omega)$ nitro- $L$-arginine (fig. 1 , c), an active metabolite of $\mathrm{N}(\omega)$-nitro- $L$-arginine methylester (fig. 1,d), which is more lipophilic than the other arginine analogs and therefore is able to penetrate the cell membrane, and finally

iii) $\mathrm{N}(\omega)$-amino- $L$-arginine (fig. $1 \mathrm{e}$ ) have been synthesized $(5-7)$ as prototype arginine analogs. These $\mathrm{N}^{\mathrm{G}}$ substituted $L$-arginine analogs have been extensively used to inhibit NO synthase activity in vitro and in vivo (5), but their specificity is limited (8).

In the guanidino group, the isosteric replacement of the terminal imine function by a sulphur atom gave rise to a new class of inhibitors including $L$-thiocitrulline (9) (fig. $1, \mathrm{f}$ ), while the replacement of the $\mathrm{NH}_{2}$ function by a S-alkyl group led to compounds such as S-methyl (fig. 
$1, \mathrm{~g}$ ) or S-ethyl- $L$-isothiocitrulline (fig. $1, \mathrm{~h}$ ). The latter compounds are shown to be potent, reversible and slowbinding inhibitors of all NO synthases but are, respectively, 10- and 50-fold more potent inhibitors of neuronal than endothelial NO synthases (10).

It appears that the guanidine moiety of $L$-arginine -NH$\mathrm{C}(=\mathrm{NH})-\mathrm{NH}_{2}$ is the pharmacophore group. This fact prompted the study of anti-NO synthase properties of non-amino acid based inhibitors (fig. 2) such as aminoguanidine (fig. 2, a) containing a hydrazine moiety that might confer selectivity for the inducible NO synthase (11). The N,N'-1,3-diaminoguanidine compound (fig. $2, \mathrm{~b})$, which appeared to be selective for inducible NO synthase (12), seemed less potent than aminoguanidine. The most potent inhibitors of inducible NO synthase among the guanidino group seemed to be mercaptopropyl and mercaptoethylguanidine (13) (fig. 2, c).

Among the N,N'-(alkane-1, $\omega$-diyl) bis (guanidine) compounds, arcaine (fig. 2, d), the 1,4-diguanidino-butane exhibited a moderate inhibition of NO synthases (14).

In the $-\mathrm{NH}-\mathrm{C}(=\mathrm{NH})-\mathrm{NH}_{2}$ guanidine moiety the secondary amine isosteric replacement by a sulfur atom gave rise to a new class of S-substituted isothiourea compounds called the ITU group R-S-C $(=\mathrm{NH})-\mathrm{NH}_{2}$, (fig. 2 ,e) which appeared to be strong inhibitors of NO syn-

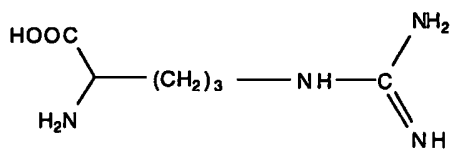

a. L-Arginine

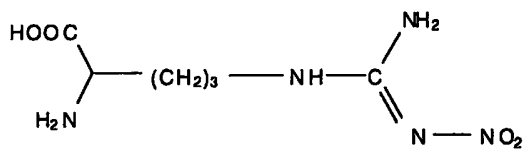

c. $\mathrm{N} \omega$-Nitro- $L$-arginine

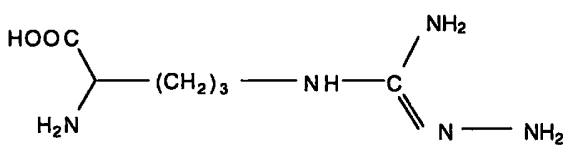

e. N $\omega$-Amino- $L$-arginine

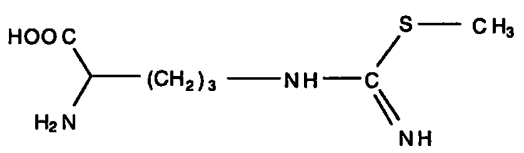

g. S-Methyl-L-isothiocitrulline thases (15-17). S-ethyl-isothiourea and S-isopropylisothiourea seemed to be the most potent structures of the straight chain, while extension of the side chain $R$ decreased the potency ( $n$-propyl $>t$-butyl $>n$-butyl) (15). Another isothiourea potent group was bis-isothiourea (fig. 2, f), in which sulphur atoms of two isothiourea units were linked by a carbon chain, containing eventually unsatured (hetero)cyclic rings. Some of these bis isothioureas showed marked selectivity for the human inducible NO synthase when compared to constitutive NO synthases. The bis-isothiourea, S,S'-(1,3-phenylenebis(1,2-ethanediyl)bis-isothiourea (fig. 2,g) was 190-fold more selective for the inducible NO synthase than for endothelial NO synthase (15).

Guanidine and isothiourea can be classified as derivatives of amidine. The propionamidine compound (fig. $2, \mathrm{~h}$ ) and longer chained amidines inhibited the inducible NO synthase (18).

Here was examined the ability of some S,S'-(alkane$1, \omega$-diyl) bisisothiouronium dibromides and $\mathbf{N}, \mathbf{N}^{\prime}$-(alkane-1, $\omega$-diyl) bisguanidinium dinitrates and the newly synthesized N,N'-bis (3-guanidinopropyl)piperazine dinitrate to inhibit, in the rat, NO generation in the course of an inflammatory reaction. Some of these compounds (bisisothiouronium salts) have already been<smiles>CN=C(N)NNCCCC(N)C(=O)O</smiles>

b. N $\omega$-Monomethyl- $L$-arginine<smiles></smiles>

d. N $\omega$-Nitro- $L$-arginine methylester<smiles>NC(=S)NNCCCC(N)C(=O)O</smiles>

f. $L$-Thiocitrulline<smiles>CSC(=N)NCCCC(N)C(=O)O</smiles>

h. S-Ethyl- $L$-isothiocitrulline

Fig. 1 Chemical structure of $L$-arginine based inhibitors of NO synthases. 


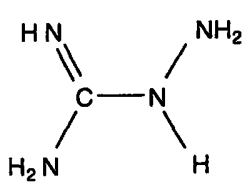

a. Aminoguanidine<smiles>N=C(N)NPS</smiles>

c. Mercaptoethyl(or propyl)guanidine<smiles>N=C(NN)NN</smiles>

b. $\mathrm{N}, \mathrm{N}^{\prime}-1,3-$ Diaminoguanidine<smiles>N=C(N)CCCCCNC(=N)N</smiles>

d. Arcaine<smiles>[R]SC(=N)N</smiles>

e. Isothiourea compounds<smiles>N=C(N)PPSC(=N)N</smiles>

f. Bis isothiourea compounds<smiles>N=C(N)SCCc1cccc(CCSC(=N)N)c1</smiles>

g. S,S'-(1,3-Phenylenebis(1,2-ethanediyl)bis isothiourea<smiles>CCC(=N)N</smiles>

h. Propionamidine

Fig. 2 Chemical structure of non-amino acid based inhibitors of NO synthases.

tested in vitro, but not in vivo (15). To our knowledge, the bisguanidinium salts were already synthesized but tested neither in vitro nor in vivo as NO synthase inhibitors.

We explored the potential selectivity of these agents towards constitutive and inducible isoforms of NO synthases in comparison to the activity of 2-methyl-2-thiopseudourea sulphate previously described as a potent NO synthase inhibitor by Southan et al. (16) and considered as the reference compound.

\section{Material and Methods}

\section{Chemicals}

Two S,S'-(alkane-1, $\omega$-diyl) bisisothiouronium dibromides have been synthesized according to the method described by Garvey et al. (15).

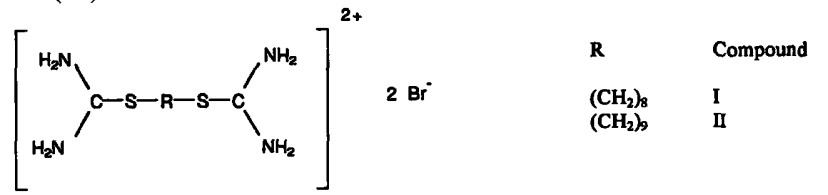

Three N,N'-(alkane-1, $\omega$-diyl) bisguanidinium dinitrates were synthesized according to the method described by Tesman et al. (19).<smiles>NC(N)NPNC(N)C1CCCCC1</smiles>

Synthesis of $N, N^{\prime}$-bis (2-guanidinopropyl) piperazine dinitrate (compound VI)<smiles>NC(N)NCCN1CCN(CCNC(N)[18F])CC1</smiles>

$4.02 \mathrm{~g}(0.02 \mathrm{~mol})$ of 3,5-dimethylpyrazol-1-carboxamidine nitrate were added to a solution of $2 \mathrm{~g}(0.01 \mathrm{~mol})$ of $1,4 \mathrm{bis}$ (3-aminopropyl) piperazine in $50 \mathrm{ml}$ of ethanol. The mixture was refluxed for 5 hours and cooled. The white precipitates were collected by drying, washed with $20 \mathrm{ml}$ of acetonitrile and $50 \mathrm{ml}$ diethylether to yield $3.7 \mathrm{~g}(90 \%$ of theory) of the bis-guanidinium salt (ethanol) (m. p. $=218^{\circ} \mathrm{C}$ ). Infrared spectroscopy (KBr): 3300, 3285, 3200, 2978, 2825, 2820 , $\left(\mathrm{NH}_{2}^{+}\right) \mathrm{cm}^{-1}$.

$\mathrm{H}$ nuclear magnetic resonance $\mathrm{d}_{6}: 7.43,6.82\left(\mathrm{~m}, 10 \mathrm{H}, \mathrm{NH}_{2}^{+}\right), 3.10$, $2.35,2.29,1.62\left(\mathrm{~m}, 20 \mathrm{H},\left(\mathrm{CH}_{2}\right)_{3}, \mathrm{CH}_{2}\right.$ piperazine) $\mathrm{ppm}$.

Elementary analysis for $\mathrm{C}_{12} \mathrm{H}_{30} \mathrm{~N}_{10} \mathrm{O}_{6}\left(M_{\mathrm{r}} 410.41\right)$.

Calculated: C, 35.11\%; H, 7.36\%; N, 34.12\%.

Found: C, $35.21 \% ; \quad H, 7.42 \% ; \quad \mathrm{N} ; 34.18 \%$. 
Carrageenan $\lambda$ was obtained from Pierrefitte Auby (Neuilly/Seine, France) Hank's solution (without phenol red), N-(1-naphthyl)-ethylenediamine, and sulphanilamide were purchased from Sigma Chemical Co. (St. Louis, Mo, USA). Phosphoric acid was purchased from Merck (Darmstadt, Germany) and 2 methyl-2-thiopseudourea sulphate was purchased from Aldrich (Steinheim, Germany).

\section{Animals and treatments}

Male Sprague-Dawley rats weighing $180-200 \mathrm{~g}$ (Dépré, SaintDoulchard, France) were used for all experiments (20). Protocols were submitted and approved by the local ethics committee.

Pleurisy was induced by intrapleural injection of $0.1 \mathrm{ml}$ of $10 \mathrm{~g} / 1$ carrageenan $\lambda$ suspension in saline (21).

The methyl 2-thiopseudourea sulphate, bisisothiouronium and bisguanidinium salts $(0.1 \mathrm{ml})$ were administered with the inflammatory stimulus into the pleural cavity at concentrations varying from $5 \times 10^{-6}$ to $10^{-4} \mathrm{~mol} / 1$.

Animals were euthanized with ether, and the right pleural cavity was opened for pleural exudate collection at $30 \mathrm{~min}(\mathrm{t}=0.5 \mathrm{~h})$ or seven hours $(t=7 \mathrm{~h})$. Samples were centrifuged at $500 \mathrm{~g}$ for $5 \mathrm{~min}$, and the supernatants were then centrifuged at $1000 \mathrm{~g}$ for $20 \mathrm{~min}$ in order to remove exudate fibrin. Samples were then adjusted to a final volume of $1 \mathrm{ml}$ with $H a n k$ 's solution and stored at $-80^{\circ} \mathrm{C}$ until nitrite determination was carried out.

\section{Nitrite determination in pleural exudate}

Nitrite was measured in pleural exudates as an indicator of NO formation (22). Aliquots of $0.1 \mathrm{ml}$ were incubated in individual wells of a 96-well plate, with $0.1 \mathrm{ml}$ of Griess reagent $(0.5 \mathrm{~g} / \mathrm{l} \mathrm{N}$ (1-naphthyl)-ethylenediamine and $5 \mathrm{~g} / 1$ sulphanilamide in phosphoric acid $(50 \mathrm{~g} / \mathrm{l})$, at room temperature for $10 \mathrm{~min}$. The absorbance was measured at $550 \mathrm{~nm}$ using a microplate reader (Dynatech, MRX), in comparison with the incubating medium (Hank's solution) without cells. Sodium nitrite was used to establish a nitrate standard curve.

\section{Statistical analysis}

The Mann-Whitney U test (in the computer program Statview II) was carried out in each group between treated and nontreated rats. Results were given as a mean \pm SEM. Differences with $\mathrm{p}<0.05$ were considered as significant.

\section{Results}

NO generation was assessed 0.5 and 7 hours after the induction of the inflammatory reaction. According to previous studies (23) this production correlated to the activation of constitutive and inducible NO synthases respectively.

In a first series of experiments, bisthiouronium salts at a dose of $5 \times 10^{-5} \mathrm{~mol} / 1$ showed a similar inhibiting effect to that exerted by the same dose of the reference compound (2-methyl-2-thiopseudourea sulphate). This dose was chosen in accordance to previous studies (23) that demonstrated activity of this reference compound. S,S'-(octane-1,8-diyl) bisisothiouronium dibromide (compound I) was the major effective compound at $0.5 \mathrm{~h}$ and $\mathrm{S}, \mathrm{S}^{\prime}$-(nonane-1,9-diyl) bisisothiouronium dibromide (compound II) at $7 \mathrm{~h}$.

These results led us to examine the effect exerted by these compounds compared to the reference compound in a concentration range varying from $5 \times 10^{-6} \mathrm{~mol} / 1$ and up to $10^{-4} \mathrm{~mol} / 1$ after the induction of pleurisy by carrageenan $\lambda$. Similar results were obtained with the three compounds at $0.5 \mathrm{~h}$ for the constitutive NO synthase (fig. 3). The inhibiting effect was most striking on nitrite generation measured 7 hours after the beginning of the inflammatory reaction and reflecting the inducible NO synthase stimulation. The dose of $5 \times 10^{-5} \mathrm{~mol} / 1$ was the most effective for compound I. Compound II seemed to be a more potent inhibitor than compound I at $7 \mathrm{~h}$, and quite similar to the reference compound at the three doses tested (fig. 4).

Figure 5 shows the effects produced by the bisguanidinium compounds (compounds III, IV, V), compound VI and the reference compound at 0.5 and $7 \mathrm{~h}$ after the induction of pleurisy. Results were significantly different from controls at $0.5 \mathrm{~h}$, only with the $\mathrm{N}, \mathrm{N}^{\prime}$ (heptane-1,7diyl) bisguanidinium dinitrate (compound IV) and N,N'bis (3-guanidinopropyl) piperazine dinitrate (compound VI). At $7 \mathrm{~h}$, all the results were significantly different from controls, with a major effect observed with compound IV and the reference compound.

\section{Discussion}

These bisisothiouronium and bisguanidinium salts demonstrated the inhibiting effect on NO generation in the course of carrageenan-induced pleurisy, as well as 2methyl-2-thiopseudourea sulphate previously studied in vitro by Southan et al. (16). Their activity is most significant against inducible rather than constitutive NO synthases. However, the specificity of the compounds in

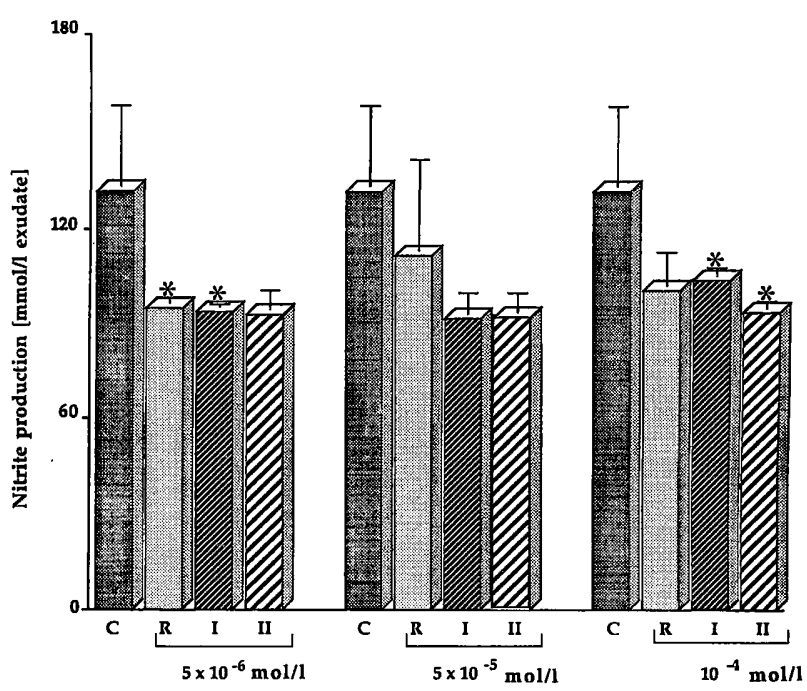

Fig. 3 Nitrite production ( $\overline{\mathrm{x}} \pm$ S. E. M.) in the pleural cavity 0.5 hour after injection of $0.1 \mathrm{ml}$ of carrageenan $\lambda(10 \mathrm{~g} / \mathrm{l})$.

In vivo effects of various concentrations $\left(5 \times 10^{-6}-1 \times 10^{-4}\right.$ $\mathrm{mol} / \mathrm{l}$ ) of 2-methyl-2-thiopseudourea sulphate (reference: R), S,S'(octane-1,8-diyl)bisisothiouronium (compound I), S,S'-(nonane1,9-diyl)bisisothiouronium (compound II).

C: controls. Number of animals included in each group $n=6$. $* \mathrm{p}<0.05$ 
relation to the various isoforms of NO synthases varies from one compound to another, but without a strict cor-

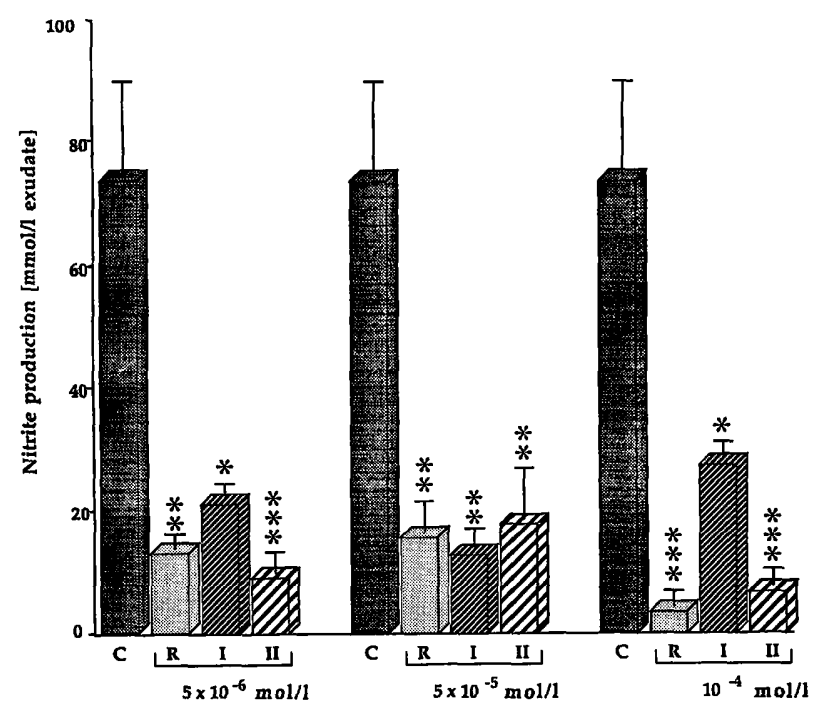

Fig. 4 Nitrite production ( $\overline{\mathrm{x}} \pm$ S.E.M.) in the pleural cavity 7 hours after injection of $0.1 \mathrm{ml}$ of carrageenan $\lambda(10 \mathrm{~g} / 1)$. In vivo effects of various concentrations $\left(5 \times 10^{-6}-1 \times 10^{-4}\right.$ $\mathrm{mol} / \mathrm{l}$ ) of $\mathrm{R}$, compounds I and II.

$\mathrm{n}=6$. C: controls.

${ }^{*} \mathrm{p}<0.05,{ }^{* *} \mathrm{p}<0.01,{ }^{* * *} \mathrm{p}<0.001$

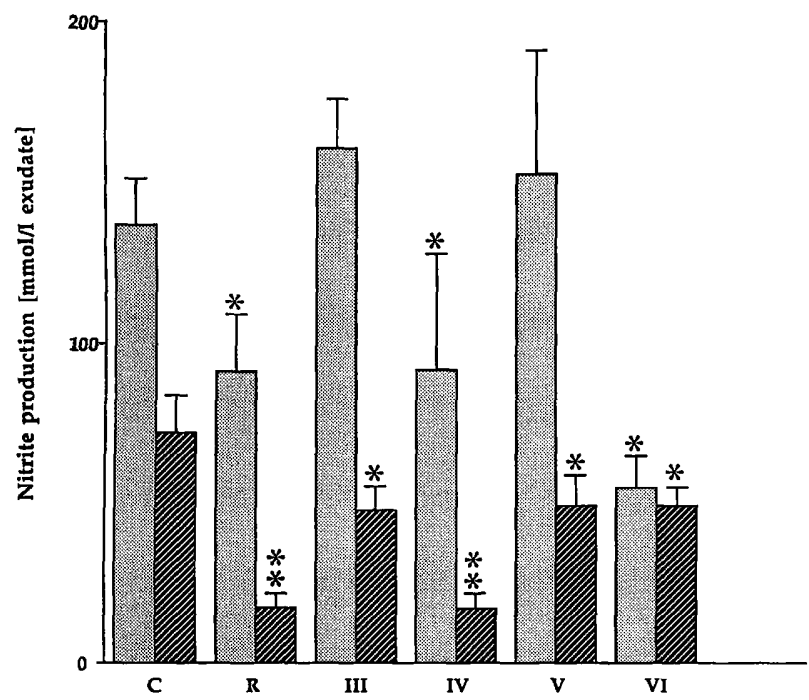

Fig. 5 Nitrite production ( $\overline{\mathrm{x}} \pm$ S. E. M.) in the pleural cavity $0.5 \square$ and 7 hours after injection of $0.1 \mathrm{ml}$ of carrageenan $\lambda(10$ $\mathrm{g} / \mathrm{l})$. C: controls.

In vivo effects of $5 \times 10^{-5} \mathrm{~mol} / 1$ of 2-methyl-2-thiopseudourea sulphate and

$\mathrm{N}, \mathrm{N}^{\prime}$-(hexane-1,6-diyl) bisguanidinium dinitrate (compound III), N,N'-(heptane-1,7-diyl) bisguanidinium dinitrate (compound IV), $\mathrm{N}, \mathrm{N}^{\prime}$-(octane-1,8-diyl) bisguanidinium dinitrate (compound $\mathrm{V}$ ), and $\mathrm{N}, \mathrm{N}$-bis (3-guanidinopropyl) piperazine dinitrate (compound VI). $\mathrm{n}=6 .{ }^{*} \mathrm{p}<0.05,{ }^{* *} \mathrm{p}<0.01$ relation to the chain length and to the dose. No clear reason was found for the lack of dose-response relationship, even for the reference compound. In previous experiments, we have determined that $5 \times 10^{-5} \mathrm{~mol} / \mathrm{l}$ of 2-methyl-2-thiopseudourea sulphate was sufficient for the inhibition of NO synthases, which was never complete even after administration of higher doses. Similar phenomenon could be observed with the bisthiouronium and bisguanidinium salts.

Garvey et al. (15) measured the apparent $\mathrm{K}_{\mathrm{i}}$ values for inducible and constitutive NO synthases using various non-amino acid isothioureas. For the S-methylisothiourea, the $K_{i}$ values obtained by measuring percent inhibition with at least three concentrations of the inhibitor for inducible, constitutive endothelial and neuronal NO synthases were $0.12,0.2$ and $0.16 \mu \mathrm{mol} / 1$ respectively. Some elements of the straight chain bisisothiourea showed moderate anti-NO synthase activities (15). S,S'-(ethane-1,2-diyl) bisisothiouronium and S,S'-(heptane-1,7-diyl) bisisothiouronium exhibit the smallest values of $\mathrm{K}_{\mathrm{i}}(1.4$ and $0.8 \mu \mathrm{mol} / \mathrm{l})$ for the inducible NO synthase. Extension of the central chain $R$ decreased the potency by increasing $K_{i}$ values for inducible NO synthase (up to $40 \mu \mathrm{mol} / 1$ for the S,S'(butane-1,4-diyl) bisisothiouronium). Consequently, $\mathrm{S}, \mathrm{S}^{\prime}$-(propane-1,3-diyl) bisisothiouronium and $\mathrm{S}, \mathrm{S}^{\prime}$-(butane-1,4-diyl) bisisothiouronium compounds are clearly not inhibitors. Unfortunately, compound II was not investigated by Garvey et al. (15) and we could not establish any relationship between their in vitro data and our in vivo results.

The potential therapeutic role of NO synthase inhibitors depends on the importance of NO release in pathological situations (24). The full therapeutic potential will be defined when NO protective functions are maintained and when only over-production (with potential proinflammatory properties) is decreased. Actually, potential therapeutic application of agents that modulate NO is emerging for the treatment of inflammatory disease, pulmonary hypertension, radioresistance of tumour cells, septic shock and vascular restenosis following angioplasty (25).

\section{Acknowledgements}

The authors would like to thank Mrs. M. Lenoir and Mr. O. Muntaner for their excellent technical assistance.

\section{References}

1. Hibbs JB, Taintor RR, Vavrin Z. Macrophage cytotoxicity: role for $L$-arginine deiminase and iminonitrogen oxidation to nitrite. Science 1987; 235:473-6.

2. Schmidt HH, Pollock JS, Nakane M, Gorsky LD, Föstermann U, Murad F. Purification of a soluble isoform of guanylyl

cyclase-activating factor synthase. Proc Natl Acad Sci USA 1991; 88:365-9.

3. Moncada S, Higgs A. The L-arginine-nitric oxide pathway. New Engl J Med 1993; 329:2002-12. 
4. Southan GJ, Szabo C. Selective pharmacological inhibition of distinct nitric oxide synthase isoforms. Biochem Pharmacol 1996; 51:383-94.

5. Gross SS, Stuehr DJ, Aisaka K, Jaffe EA, Levi R, Griffith OW. Macrophage and endothelial cell nitric oxide synthesis: cell-type selective inhibition by $\mathrm{N}^{\mathrm{G}}$-aminoarginine, $\mathrm{N}^{\mathrm{G}}$-nitroarginine and $\mathrm{N}^{\mathrm{G}}$-methylarginine. Biochem Biophys Res Commun $1990 ; 170: 95-103$.

6. Southan GJ, Gross SS, Vane JR. Amides and esters of N(w) nitro-L-arginine (e.g. L-NAME) must be hydrolyzed to become active NO synthase inhibitors. Brit J Pharmacol 1993; 109:12-8.

7. Marletta MA. Approaches toward selective inhibition of nitric oxide synthase. J Med Chem 1994; 37:1899-907.

8. Lambert LE, Whitten JP, Baron BM, Cheng HC, Doherty NS McDonald IA. Nitric oxide synthesis in the CNS, endothelium and macrophages differs in its sensitivity to inhibition by arginine analogues. Life Sci 1991; 48:69-75.

9. Narayanan K, Griffith OW. Synthesis of L-thiocitrulline, Lhomothiocitrulline and S-methyl-L-thiocitrulline, a new class of potent nitric oxide synthase inhibitors. J Med Chem 1994; 37:885-7.

10. Furfine ES, Harmon MF, Paith JE, Knowles RG, Salter M, Kiff $\mathrm{RJ}$, et al. Potent and selective inhibition of human nitric oxide synthases. Selective inhibition of neuronal nitric oxide synthase by S-methyl-L-thiocitrulline and S-ethyl-L-thiocitrulline. J Biol Chem 1994; 269:26677-83.

11. Hasan K, Heesen BJ, Corbett A, McDaniel ML, Chang K, Allison $\mathrm{W}$, et al. Inhibition of nitric oxide formation by guanidines. Eur J Pharmacol 1993; 249:101-6.

12. Corbett JA, Tilton RG, Chang K, Hasan KS, Ido Y, Wang JL et al. Aminoguanidine, a novel inhibitor of nitric oxide formation, prevents diabetic vascular dysfunction. Diabetes 1992, 41:552-6.

13. Southan GJ, Salzman AL, Szabo C. Mercapto alkyle guanidines: a novel class of inhibitors of the inducible form of nitric oxide synthase. FASEB J 1995; 9(3) A28.

14. Yokol J, Kabuto H, Habu H, Inada K, Toma J, Mori A. Structure-activity relationships of arginine analogues on nitric oxide synthase activity in the rat brain. Neuropharmacology 1994; $33: 1261-5$
15. Garvey EP, Oplinger JA, Tanoury GJ, Sherman PA, Fowler M, Marshall S, et al. Potent and selective inhibition of human nitric oxide synthases. Inhibition by non-aminoacid and isothioureas. J Biol Chem 1994; 269:26669-76.

16. Southan GJ, Szabo C, Thiemermann C. Isothioureas: potent inhibitors of nitric oxide synthases with variable isoform selectivity. Brit J Pharmacol 1995; 114:510-6.

17. Stratman N, Fici GJ, Sethy VH. U-19451A: a selective inducible nitric oxide synthase inhibitor. Life Sci 1996; 59:945-51.

18. Southan GJ, Szabo C, O'Connor MP, Salzman AL, Thiemermann C. Amidines are potent inhibitors of nitric oxide synthases: preferential inhibition of the inducible isoform. Eur J Pharmacol 1995; 291:311-8.

19. Tesman H, Weinrich E, Lieske E. (Henkel K. G. a. A.) U.S. 4,226, 852 (cl. 424-62; A 61 K7/135), 07 Oct 1980.

20. Giroud JP, Roch-Arveiller M, Muntaner O. Prélèvement répété des polynucléaires dans la cavité pleurale du rat. Application à la mesure du chimiotactisme. Nelle Rev Fse Hematol 1978; 20:535-43.

21. Roch-Arveiller M, Dunn CJ, Giroud JP. Comparaison des propriétés inflammatoires des fractions $\lambda$ and $\kappa$ de carragénine. $J$ Pharmacol 1977; 8:461-76.

22. Marletta MA, Yoon PS, Iyengar R, Leaf CD, Wishnok JS. Macrophage oxidation of L-arginine to nitrite and nitrate: nitric oxide is an intermediate. Biochemistry 1988; 27:8706-11.

23. Regnault C, Roch-Arveiller M, Florentin I, Giroud JP, Postaire E, Delaforge M. Kinetic evaluation of nitric oxide production in pleural exudate after induction of two inflammatory reactions in the rat. Inflammation 1996; 20:613-20.

24. Pfeilschifter J, Eberhardt W, Hummel R, Kunz D, Mühl H, Nitsch $D$, et al. Therapeutic strategies for the inhibitors of inducible nitric oxide synthase. Potential for a novel class of anti-inflammatory agents. Cell Biol International 1996; 20:51-8.

25. Kilbourn R. Nitric oxide: moving towards the clinic. Molec Med ToDay 1996; 2:324.

\section{Received April 21/July 24, 1997}

Corresponding author: Dr. Monique Roch-Arveiller, Laboratoire de Pharmacologie, Hôpital Cochin, Pavillon Gustave Roussy, 27, rue du Faubourg Saint-Jacques, F-75679 Paris Cedex 14, France 